Hydraulic Engineering Repository

Ein Service der Bundesanstalt für Wasserbau

De Sonneville, B.; Rudolph, Daniel; Raaijmakers, Tim

Scour Reduction by Collars Around Offshore Monopiles

Verfügbar unter / Available at:

https://hdl.handle.net/20.500.11970/100316

Vorgeschlagene Zitierweise / Suggested citation:

De Sonneville, B.; Rudolph, Daniel; Raaijmakers, Tim (2010): Scour Reduction by Collars Around Offshore Monopiles. In: Burns, Susan E.; Bhatia, Shobha K.; Avila, Catherine M. C.; Hunt, Beatrice E. (Hg.):

Proceedings 5th International Conference on Scour and Erosion (ICSE-5), November 7-10, 2010, San Francisco, USA. Reston, Va.: American Society of Civil Engineers. S. 460-470. 


\title{
Scour Reduction by Collars Around Offshore Monopiles
}

\author{
B. de Sonneville', D. Rudolph ${ }^{2}$ and T.C. Raaijmakers ${ }^{3}$
}

1Deltares | Delft Hydraulics, Rotterdamseweg 185, P.O. Box 177, 2600 MH Delft, The Netherlands; e-mail:ben.desonneville@deltares.nl

${ }^{2}$ Deltares | Delft Hydraulics, Rotterdamseweg 185, P.O. Box 177, 2600 MH Delft, The Netherlands; e-mail:daniel.rudolph@deltares.nl

${ }^{3}$ Deltares | Delft Hydraulics, Rotterdamseweg 185, P.O. Box 177, 2600 MH Delft, The Netherlands; e-mail:tim.raaijmakers@deltares.nl

Excessive scour is a threat to the stability of monopile foundations, e.g. in offshore windparks. Particularly in shallow waters with strong tidal currents such as the North Sea, protection against excessive scouring is required. Commonly applied scour protection consists of loose rock. Little is known about alternative scour protection measures. One of the alternatives is to use a collar installed around the base of the monopile at seabed level. Indicative laboratory experiments were conducted to investigate whether collars reduce pile scouring under combined current and waves. This paper summarizes the experimental set-up, monitoring techniques, test program and results of the conducted experiments. The analysis focused on the equilibrium scour depth and the rate of scour development. The results showed that collars prevented pile scour under currents. Under extreme storm conditions scour occurred, but with a significant time delay, at a lower rate and a reduced equilibrium scour depth.

\section{INTRODUCTION}

Global climate change and the related endeavour of many European governments to stimulate sustainable energy generation have drawn the attention of politics and industry to offshore wind park development. Wind turbine foundations usually consist of monopiles, which are equipped with scour protection because excessive scour can threaten their stability and affect their resonance frequency. The commonly applied scour protection consists of several rock layers.

In recent years, several alternatives have been proposed in order to control scour at piles. They are generally characterized as either altering the flow (e.g. splitter plates, slots, vanes, helical wires) or armouring the seabed (e.g. gravel bags, block matrasses, tetra pods). One of the alternatives might be to use a pre-fabricated collar installed around the base of the monopile at seabed level. The idea of such a collar under current attack is to armour the seabed by preventing downflow and horseshoe vortex development from reaching the seabed. Under waves, the collar is expected to limit wave-induced vortices and turbulence from reaching the seabed. 
Previous studies on the scour reduction of collars mainly focused on current-induced scour around bridge piers (e.g. Kumar, 1999). According to these studies, collars can be particularly effective with collar widths larger than 0.5 times the pile diameter when placed close to the bed (see Figure 1 for definitions). A more recent study (Simon et al., 2009) investigated the effect of multiple discs installed at the base of a monopile on current-induced scour with beneficial results for collar widths larger than one pile diameter. Research performed for a comparative concept (cylindrical piles with cone shaped footings) indicated a 50-80\% reduction in scour depth compared to a single pile (Rudolph and Raaijmakers, 2007).

To the authors' knowledge, to date there has been no study of the performance of collars under forcing by a combination of a current and waves, as typical in the offshore environment, and the effect of a collar on the time scale of the scour development. The aim of the study presented here is to focus on both aspects. The study was based on indicative laboratory experiments. This paper describes the conducted laboratory experiments (sections 2 and 3), analysis of the results (section 4), conclusions (section 5) and a discussion (section 6).

\section{SETUP OF LABORATORY EXPERIMENTS}

Until a few years ago, one of the major shortcomings of laboratory experiments in a wave basin was that scour development was not visible during test execution because of the turbidity of water at high sediment concentrations. Scour hole inspection required drainage of the wave basin. Since this process takes relatively long (several hours, due to the low permeability of the fine sand in the basin), it was not feasible to monitor scour development without time-consuming drainings of the basin.

In 2007, a scour monitoring technique was developed, based on installing a rotating downward facing digital camera with an inclined mirror inside a transparent model during a test (Raaijmakers and Rudolph, 2008). Recently, this technique was innovated by equipping the camera with a fish-eye lens (see Figure 2). High frequency recording of images, combined with automatic image processing software, currently allows for continuous $360^{\circ}$ monitoring of the scour development during each test. On each image the interface between water and seabed is detected automatically based on the colour gradient, and converted to a scour depth using calibration functions. This makes it possible to observe whether equilibrium was reached, at which location around the pile maximum scour depths occurred and at which rate the scour developed. 


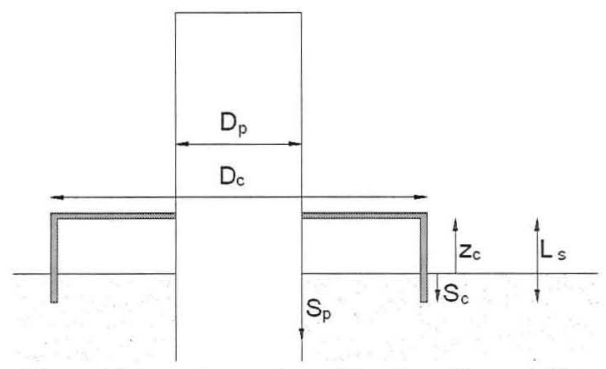

Figure 1 Schematic overview of the pile, collar and skirt setup and definitions.

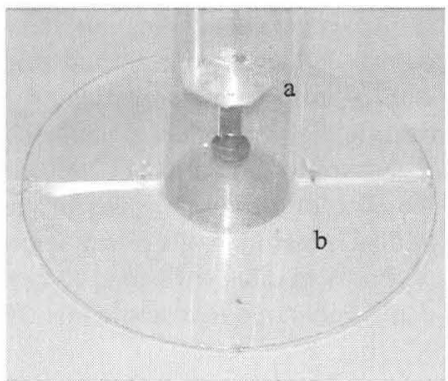

Figure 2 Design of system showing the camera mounted inside the transparent pile

(a) and the transparent collar (b).

In the experiment setup, four transparent circular piles with a diameter of $200 \mathrm{~mm}$ were equipped with the above described camera system and mounted at the bottom of the facility. During each test, one pile was left unprotected, while at the other three piles different configurations of transparent collars were installed. The solid collar discs, installed at a fixed vertical level, had a thickness of $10 \mathrm{~mm}$ with outer diameters ranging from 2-3 times the pile diameter $\left(2 D_{p}\right.$ to $3 D_{p}-$ see Figure 1$)$. In some cases, a skirt was attached to the outer diameter of the collar. All tests were performed in Deltares' Scheldt basin (30 m x 14m - see Figure 3), which is equipped with a wave generator, several pumps to generate a cross-flow of up to $2 \mathrm{~m}^{3} / \mathrm{s}$ and a bed of fine, non-cohesive sediment $\left(\mathrm{d}_{50}=130 \mu \mathrm{m}\right)$. Five wave height meters and five electromagnetic current velocity meters were installed at the outer edges of the test section.

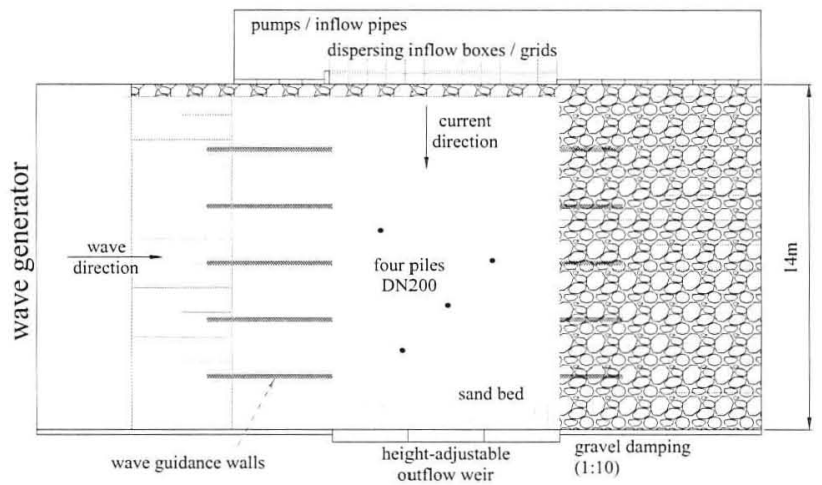

Figure 3 Overview of Scheldt Basin with wave generator at the left, current inflow from above, wave guidance walls and test section in the middle, wave spending beach at the right and outflow weirs at the bottom.

The test programme comprised six tests (see Table 1). The test conditions were guided by typical (storm) conditions occurring at the North Sea, scaled with the Froude criterion with a scale factor of 1:20. Due to limited water depth in the 
facility, however, for the water depth a distorted Froude scaling was applied. The first test represented a current-only condition, with a flow velocity of about $0.30 \mathrm{~m} / \mathrm{s}$. Tests 2-6 comprised storm conditions with a significant wave height of about $0.27 \mathrm{~m}$ and a peak wave period of 2.3 or $3.0 \mathrm{~s}$.

\section{RESULTS OF LABORATORY EXPERIMENTS}

(1) Introduction

After all tests, the measured significant wave heights, peak wave periods and current velocities were processed and spatially interpolated to the locations of the structures in the basin. The scour development at each of the piles was processed from the camera images with the system described above (see Figure 4).

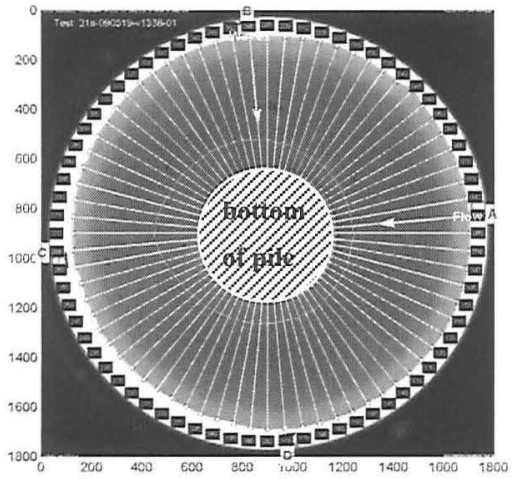

Figure 4a Camera image taken from inside pile (looking downward) at start of test $2 \mathrm{a}$. The dark area around the bottom of the pile indicates the penetration of the pile in the sand. No scour has occurred yet.

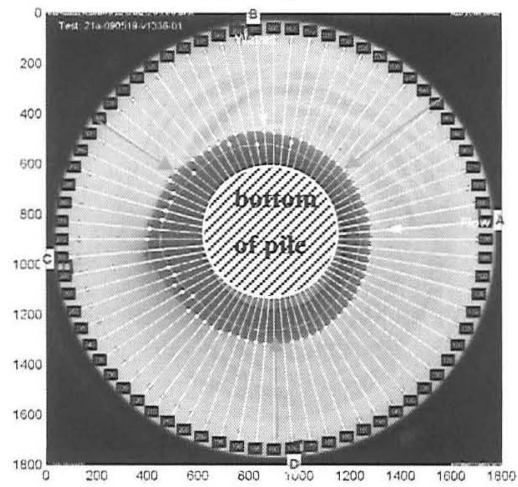

Figure 4c Camera image taken 33 minutes into the test. Additional scouring still occurs, although at a slower rate than at the start of the test.

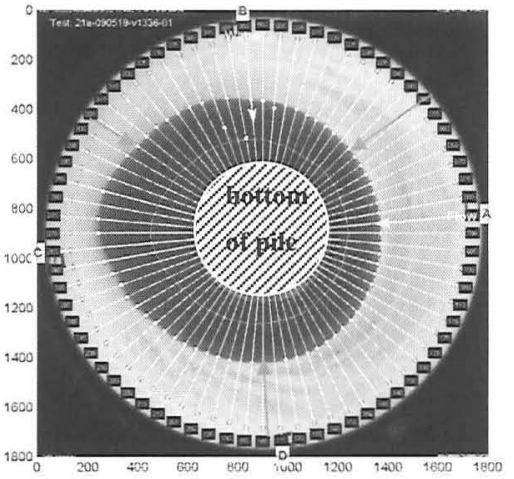

Figure $4 \mathrm{~b}$ Camera image taken 13 minutes into the test. Scour has occurred, indicated by red arrows.

The white dots show the automatically detected interface between sand and water.

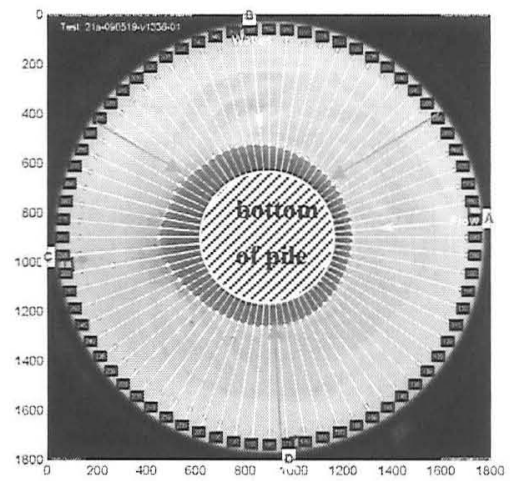

Figure 4d Camera image taken at the end of the test (after about 100 minutes), when the scour depth approaches equilibrium. 
In the following analysis the maximum pile scour at the structure $\left(\mathrm{S}_{\mathrm{p}}\right.$ - see Figure 1) is considered, and not the edge scour hole that occurs at the edge of the collar $\left(\mathrm{S}_{\mathrm{c}}\right)$. Scour at the pile is assumed the most relevant threat for the stability and resonance frequency of offshore monopiles.

According to a commonly adopted approach (e.g. Hoffmans and Verheij 1997, Whitehouse, 1998 and Sumer and Fredsce, 2002), scour development can be described by an exponential function. In this function, the timescale of scouring is described by the characteristic time ( $T_{\text {char }}$ - when $63 \%$ of the equilibrium scour depth has been reached). We adapted this function to include a delay before scouring starts $\left(t_{0}\right)$, related to the scour protection provided by the collar:

$$
\frac{S(t)}{S_{c q}}=1-\exp \left(-\frac{t_{0}+t}{T_{c h a r}}\right)
$$

For each test and each of the four piles, $\mathrm{T}_{\text {char }}$ and $\mathrm{t}_{0}$ were determined by fitting this function to the measured data. The function appeared to fit the data rather well (see Figure 5). This confirms the suitability of the assumed exponential function.

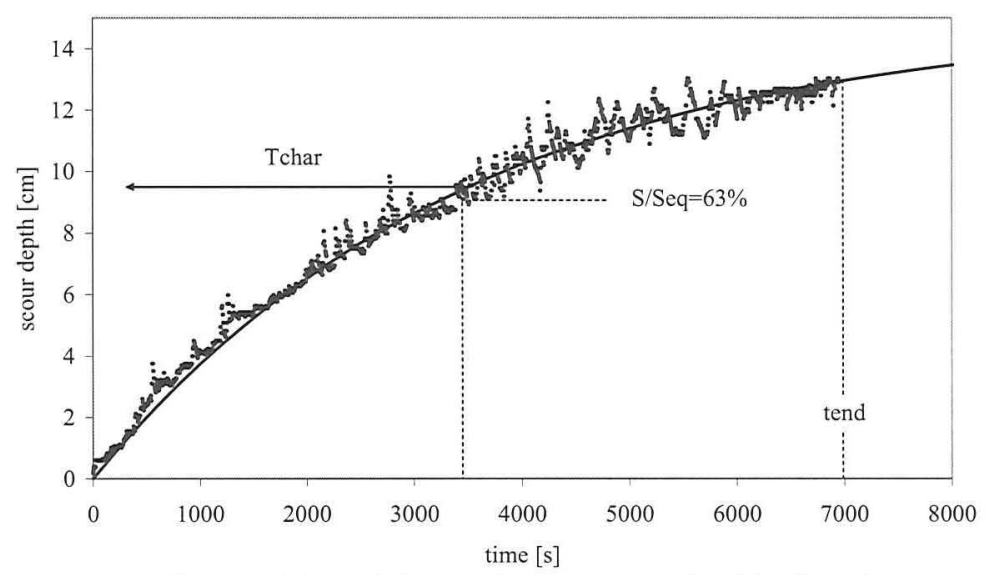

Figure 5 Example of time scale fit (test 1d) at the upstream side of the pile perimeter.

\section{(2) Test results overview}

Table 1 shows the results of the six performed tests. The piles are indicated by letters 'a' to 'd'. In test 1,2 and 5 pile 'a' represented the unprotected pile. Test 6 comprised a single pile. In some cases the scour data was not sufficient to provide a reasonable fit for the scour development, which does not mean that no scour occurred (see scour parameters marked ' $n / a$ '). 
Table 1: Test results showing the collar specifications, the processed measured hydrodynamics and the processed scour development.

\begin{tabular}{|c|c|c|c|c|c|c|c|c|c|c|c|c|c|c|}
\hline \multirow[t]{2}{*}{ test id. } & \multicolumn{3}{|c|}{ collar } & \multicolumn{8}{|c|}{ hydrodynamics } & \multicolumn{3}{|c|}{ scour } \\
\hline & $\mathrm{D}_{\mathrm{c}}[\mathrm{m}]$ & $\mathrm{L}_{\text {skin }}[\mathrm{m}]$ & $\mathrm{z}_{\mathrm{c}}[\mathrm{m}]$ & $\mathrm{h}_{\mathrm{w}}[\mathrm{m}]$ & $\mathrm{H}_{\mathrm{s}}[\mathrm{m}]$ & $\mathrm{T}_{\mathrm{p}}[\mathrm{s}]$ & $\mathrm{u}_{\mathrm{c}}[\mathrm{m} / \mathrm{s}]$ & $\mathrm{t}_{\mathrm{end}}[\mathrm{min}]$ & $\mathrm{U}_{\text {bed }}[\mathrm{m} / \mathrm{s}]$ & $\mathrm{KC}[-]$ & $\mathrm{U}_{\mathrm{ret}}[-]$ & $\mathrm{S}_{\text {cqup }}[\mathrm{m}]$ & $\mathrm{t}_{0}[\mathrm{~s}]$ & $\mathrm{T}_{\text {char }}[\mathrm{s}]$ \\
\hline $1 \mathrm{a}$ & 0.00 & 0.00 & 0.00 & 0.75 & 0.000 & 0.00 & 0.28 & 120 & 0.000 & 0.0 & 0.00 & 0.16 & 0 & 3500 \\
\hline $1 \mathrm{~b}$ & 0.40 & 0.00 & 0.00 & 0.75 & 0.000 & 0.00 & 0.28 & 120 & 0.000 & 0.0 & 0.00 & 0.00 & $\mathrm{n} / \mathrm{a}$ & $\mathrm{n} / \mathrm{a}$ \\
\hline $1 \mathrm{c}$ & 0.50 & 0.00 & 0.00 & 0.75 & 0.000 & 0.00 & 0.29 & 120 & 0.000 & 0.0 & 0.00 & 0.00 & $\mathrm{n} / \mathrm{a}$ & $\mathrm{n} / \mathrm{a}$ \\
\hline 1d & 0.60 & 0.00 & 0.00 & 0.75 & 0.000 & 0.00 & 0.29 & 120 & 0.000 & 0.0 & 0.00 & 0.00 & $\mathrm{n} / \mathrm{a}$ & $\mathrm{n} / \mathrm{a}$ \\
\hline $2 a$ & 0.00 & 0.00 & 0.00 & 0.75 & 0.269 & 3.08 & 0.25 & 100 & 0.486 & 7.5 & 0.34 & 0.15 & 0 & 1300 \\
\hline $2 \mathrm{~b}$ & 0.40 & 0.00 & 0.00 & 0.75 & 0.280 & 3.06 & 0.27 & 100 & 0.503 & 7.7 & 0.35 & $\mathrm{n} / \mathrm{a}$ & 3000 & $\mathrm{n} / \mathrm{a}$ \\
\hline $2 c$ & 0.50 & 0.00 & 0.00 & 0.75 & 0.267 & 3.00 & 0.29 & 100 & 0.477 & 7.2 & 0.37 & $\mathrm{n} / \mathrm{a}$ & 3600 & $\mathrm{n} / \mathrm{a}$ \\
\hline $2 \mathrm{~d}$ & 0.60 & 0.00 & 0.00 & 0.75 & 0.254 & 2.95 & 0.30 & 100 & 0.450 & 6.6 & 0.40 & $\mathrm{n} / \mathrm{a}$ & 3400 & $\mathrm{n} / \mathrm{a}$ \\
\hline $3 a$ & 0.40 & 0.04 & 0.00 & 0.75 & 0.283 & 2.93 & 0.28 & 60 & 0.497 & 7.3 & 0.36 & 0.00 & $\mathrm{n} / \mathrm{a}$ & $\mathrm{n} / \mathrm{a}$ \\
\hline $3 b$ & 0.50 & 0.04 & 0.00 & 0.75 & 0.273 & 2.96 & 0.29 & 60 & 0.482 & 7.1 & 0.37 & 0.00 & $\mathrm{n} / \mathrm{a}$ & $\mathrm{n} / \mathrm{a}$ \\
\hline $3 c$ & 0.60 & 0.00 & 0.10 & 0.75 & 0.262 & 2.99 & 0.28 & 60 & 0.467 & 7.0 & 0.38 & 0.15 & 200 & 400 \\
\hline $3 d$ & 0.60 & 0.04 & 0.00 & 0.75 & 0.270 & 2.94 & 0.27 & 60 & 0.476 & 7.0 & 0.36 & 0.00 & $\mathrm{n} / \mathrm{a}$ & $\mathrm{n} / \mathrm{a}$ \\
\hline $4 a$ & 0.40 & 0.04 & 0.00 & 0.75 & 0.286 & 3.10 & 0.28 & 120 & 0.515 & 8.0 & 0.35 & $\mathrm{n} / \mathrm{a}$ & 5000 & $\mathrm{n} / \mathrm{a}$ \\
\hline $4 b$ & 0.50 & 0.04 & 0.00 & 0.75 & 0.276 & 3.03 & 0.29 & 120 & 0.493 & 7.5 & 0.37 & $\mathrm{n} / \mathrm{a}$ & 2000 & $\mathrm{n} / \mathrm{a}$ \\
\hline $4 c$ & 0.60 & 0.04 & 0.04 & 0.75 & 0.266 & 2.95 & 0.28 & 120 & 0.471 & 7.0 & 0.38 & 0.21 & 0 & 2500 \\
\hline $4 d$ & 0.60 & 0.04 & 0.04 & 0.75 & 0.271 & 2.99 & 0.28 & 120 & 0.483 & 7.2 & 0.36 & 0.20 & 0 & 3000 \\
\hline $5 \mathrm{a}$ & 0.00 & 0.00 & 0.00 & 0.75 & 0.276 & 2.40 & 0.20 & 120 & 0.432 & 5.2 & 0.32 & 0.09 & 400 & 1800 \\
\hline $5 b$ & 0.40 & 0.04 & 0.00 & 0.75 & 0.280 & 2.31 & 0.20 & 120 & 0.427 & 4.9 & 0.32 & 0.00 & $\mathrm{n} / \mathrm{a}$ & $\mathrm{n} / \mathrm{a}$ \\
\hline $5 c$ & 0.60 & 0.00 & 0.00 & 0.75 & 0.273 & 2.33 & 0.20 & 120 & 0.418 & 4.9 & 0.32 & 0.00 & $\mathrm{n} / \mathrm{a}$ & $\mathrm{n} / \mathrm{a}$ \\
\hline $5 d$ & 0.60 & 0.04 & 0.00 & 0.75 & 0.265 & 2.34 & 0.20 & 120 & 0.410 & 4.8 & 0.32 & 0.00 & $\mathrm{n} / \mathrm{a}$ & $\mathrm{n} / \mathrm{a}$ \\
\hline 6 & 0.60 & 0.00 & 0.00 & 0.75 & 0.265 & 3.00 & 0.31 & 330 & 0.473 & 7.1 & 0.39 & 0.10 & 6000 & 5500 \\
\hline
\end{tabular}

\section{ANALYSIS OF RESULTS}

\section{(1) Governing processes}

Scour around a slender cylindrical pile is governed by three hydrodynamic phenomena (Sumer and Fredsce, 2002):

- a horseshoe vortex upstream of the pile,

- $\quad$ vortex shedding at the downstream side of the pile and

- $\quad$ streamline contraction

The horseshoe vortex is the dominant phenomenon in case of current-only. As the current encounters the pile, pressure gradients drive it downward around the pile and scour occurs as result of a locally enhanced sediment transport gradient. The size of the horseshoe vortex and consequently the scour depth is mainly determined by the separation distance of the bed boundary layer of the upstream flow. The separation distance is typically in the order of the pile diameter.

In case of waves, the dominating phenomenon is vortex shedding. Each shed vortex sweeps up sediment while it is transported downstream, causing a net increase in scour depth each half wave period. The intensity of vortex shedding depends on the wave-induced water motion at the seabed relative to the pile diameter. This ratio is typically defined as the Keulegan-Carpenter number:

$K C=\frac{u_{b e d} \cdot T_{p}}{D}$

in which $\mathrm{KC}=\mathrm{Keulegan}-$ Carpenter number, $\mathrm{u}_{\mathrm{bed}}=$ amplitude of undisturbed 
bed orbital velocity (based on the significant wave height), $T_{p}=$ peak wave period and $\mathrm{D}=$ pile diameter.

In combined current and waves, the relative velocity is often used to indicate whether the current action or the wave action is dominant:

$U_{r e l}=\frac{u_{c}}{u_{c}+u_{b e d}}$ velocity

in which $\mathrm{U}_{\text {rel }}=$ relative flow velocity and $\mathrm{u}_{\mathrm{c}}=$ depth-averaged current

\section{(2) Scour at unprotected pile}

A significant amount of scouring $\left(0.8 \mathrm{D}_{\mathrm{p}}\right)$ occurred at the unprotected pile under the current-only condition (test 1a). The scour was distributed relatively symmetrically around the pile perimeter with a maximum at the upstream side and a minimum at the downstream side (see Figure 6). The characteristic time of test 1a (3500s) indicates that at the end of the test (7200s) the equilibrium scour depth was almost reached. Although the scouring was significant, it was well below the rule of thumb often used in literature, independent on the current velocity: $1.3 \mathrm{D}_{\mathrm{p}}$ (Sumer and Fredsce, 2002), and the scour prediction computed with the formula of Sheppard (2006), which is dependent on the current velocity: coincidentally also $1.3 \mathrm{D}_{\mathrm{p}}$ for test $1 \mathrm{a}$. A possible reason is that the current velocity of test $1 \mathrm{a}$ corresponds with a hydraulic regime between the clear-water scour peak and the live-bed scour peak, for which slightly lower scour depths were previously observed by various researchers, e.g. Sumer and Fredsce (2002). This is not accounted for in the formulae.

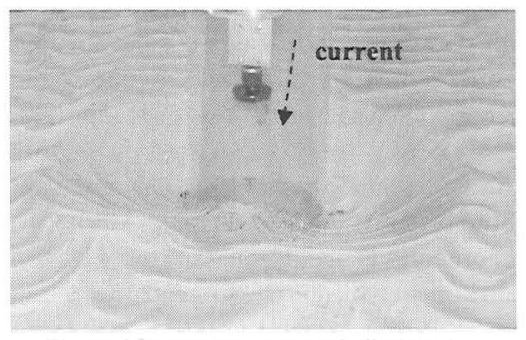

Figure 6 Scour at unprotected pile (test $1 \mathrm{a}$ current-only).

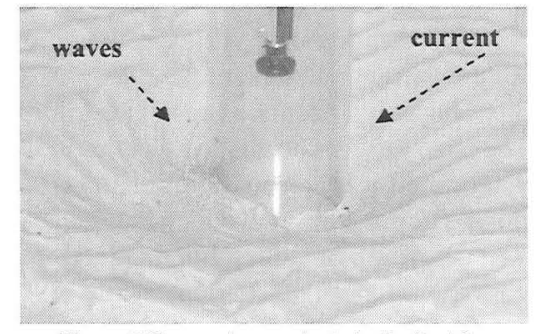

Figure 7 Scour at unprotected pile (test $2 \mathrm{a}-$ wave-dominated).

Under combined current and waves $(\mathrm{KC} \approx 7$ ), a more or less similar equilibrium scour depth occurred (test $2 a$ ) as in the current-only test (test $1 \mathrm{a}$ ). The extent of the scour hole was slightly less distinct, probably because of enhanced turbulence (see Figure 7). When compared to recent formulae on scour at unprotected circular piles under waves (Raaijmakers and Rudolph, 2008) the scour depth and scour development were in the range of predicted values. 


\section{(4) Effect of collar in current}

The effectiveness of collars was considered by comparing the scour depth at the unprotected pile with the pile scour depth at the piles protected by collars. Test 1b-d demonstrate that collars are effective under current-only conditions (see Figure 8-9). As opposed to the unprotected pile, no pile scour occurred at the piles protected by collars. Limited edge scour holes (in the order of a few $\mathrm{cm}$ ) were observed downstream around the edges of the collar (as found in Kumar et al, 1999). This indicates that the scouring is effectively shifted away from the pile and occurs in a zone where the horseshoe vortex is significantly weaker.

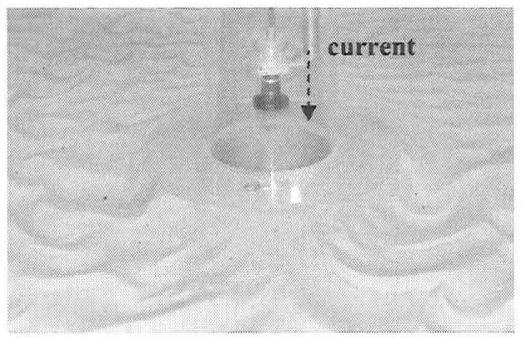

Figure 8 Edge scour at pile protected by smallest collar (test $1 b$ - current-only).

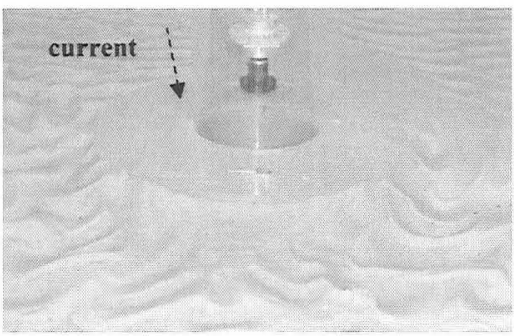

Figure 9 Edge scour at pile protected by largest collar (test $1 \mathrm{~d}$ - current-only).

(5) Effect of collar in combined waves and current

Under combined current and wave conditions (tests 2-6) collars also proved effective. Although in some cases pile scouring was not prevented completely, in all cases it was significantly delayed and reduced in depth. The general scour pattern at the end of the tests was characterised by a shallow wide depression around the edges of the collars (see Figure 10). This indicates that the scour development was not governed by the horseshoe vortex, but by wave-induced vortex shedding and turbulence. In test 3 collars with skirts were installed. With skirts, in test 3 , the delay was sufficiently long to prevent undermining (compare Figure 10 with Figure 11).

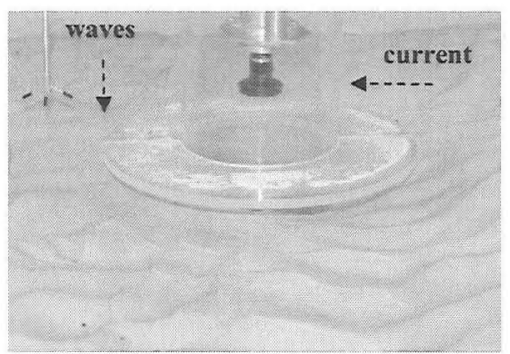

Figure 10 Scour at pile protected by smallest collar (test $2 \mathrm{~b}$ - wave-dominated).

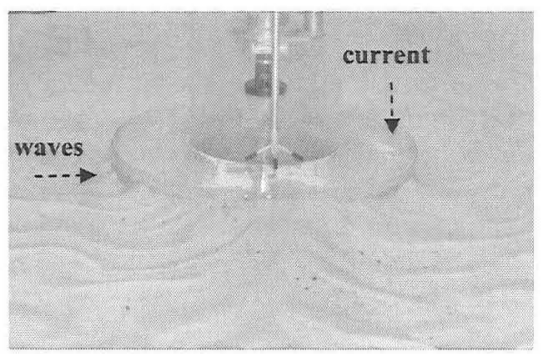

Figure 11 Scour at pile protected by largest collar with skirt (test 3a - wave-dominated). 
Analysis of the scour development of test 2 revealed that under combined current and wave conditions, after a significant time delay, pile scour occurred the piles protected by collars (see Figure 12). Two phases were distinguished: during the first phase the collar effectively protected the bed near the pile against wave-induced shed vortices while the edge scour depression grew. In the second phase, the edge scour depression presumably reached a depth at which the vortices were able to protrude under the collar and sediment was removed from underneath the collar. Test 6, which had a long duration (5.5hrs), confirmed that a $30-35 \%$ lower equilibrium scour depth was reached at the end of the test (see Figure 13).

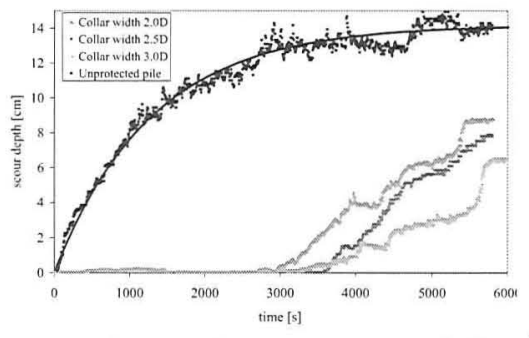

Figure 12 Scour development at unprotected pile (shown in black) and the piles protected by different collar widths (test 2).

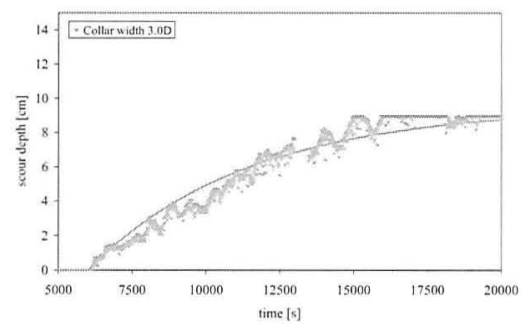

Figure 13 Scour development for pile with a collar width of 3.0D for long duration test. Note that the

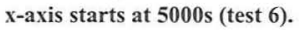

With respect to a collar at a fixed height above the bed, Kumar et al. (1999) report positive results in terms of scour reduction under current-only conditions. In our study, we did not investigate the effect of a higher collar in current-only conditions. Under combined current and wave conditions (test 3c), however, the collar placed at a height of $0.5 \mathrm{D}$ above the bed was not effective; the final scour depth was about similar to the unprotected pile, but the rate was even higher (i.e. faster scour development). It appears that a collar at a fixed height is less effective at disrupting the (horizontal) shed vortices under wave-dominated conditions than at disrupting the (predominantly vertical) horseshoe vortex under currents.

Installing skirts at the outer edge of the collars proved to be effective in terms of a larger time delay (test $2 \mathrm{~b}$ vs. $4 \mathrm{a}$ ), but when undermining occurred pile scour developed (test $4 \mathrm{a}, \mathrm{b}$ ). Collars with skirts placed at $0.5 \mathrm{D}$ above the ground (test $4 \mathrm{c}-\mathrm{d}$ ) proved to have an adverse effect: the final scour depths were even larger than at the unprotected pile under the same conditions (test $2 \mathrm{a}$ ).

\section{CONCLUSIONS}

Laboratory tests were performed to investigate the effectiveness of collars to prevent scour around offshore monopiles. Four transparent piles $(200 \mathrm{~mm})$ were placed in the Scheldt basin at Deltares and equipped with cameras with fisheye lenses. At selected piles, collars were installed with different widths, vertical levels 
and skirt dimensions. Several tests were performed with current-only and combined current and wave conditions. During each test, the scour development around the unprotected pile was derived from the camera images and compared to the pile scour development at the piles protected by collars.

The comparisons indicated that collars are quite effective against scour under currents. Only slight edge scour was observed. Under combined current and wave conditions after a significant time delay scour developed, at a lower rate and with a lower equilibrium scour depth.

Placing the collar at a certain fixed level above the bed significantly increased the scour rate under combined wave and current conditions, compared to the unprotected situation. Installing a skirt at the outer diameter of the collar worked beneficially as pile scouring was delayed, but when the skirt was undermined pile scour occurred. With the collar and skirt at a fixed level above the bed, the pile scour depth became even larger than in the unprotected scenario.

\section{DISCUSSION}

The results clearly indicate that collars have potential to provide effective offshore scour protection. Compared to conventional rock dumping, they may have the advantage of a lower material cost and, possibly, a simplified installation procedure. However, the tests also identified aspects that are in need of further investigation. One example is the importance of a good understanding of the time scale of the scour development when collars are present. The tests indicated that the severity and time duration of a storm will ultimately determine whether scour occurs at a collar-protected pile. Recommendations for future research are summarized below:

- Further testing with longer time durations and varying conditions is recommended to better understand the rate of pile scour development when a collar is present. This should include a current test with a long duration to verify whether the edge scour hole is able to undermine the collar and finally reach the pile perimeter and a series of subsequent tests with a storms and current-only conditions to study the effect of varying hydrodynamic loads and the role of initial edge scour.

- Fixation of the collar at a certain height above the seabed may worsen the scour problem under wave-dominated conditions. It should be investigated whether natural seabed variations (e.g. ripples or sand waves) could make the collar counter-effective.

- A sufficiently long skirt can prevent scour at the pile. Therefore, the minimum required skirt length and the fixation of the skirt to the pile should be further investigated.

The effect of tidal flow was not considered. Tide reversal may have an effect on the timescale of scour development.

- A flexible collar may be more effective than a stiff collar, providing that it is 
flexible enough to follow edge scour development, but heavy enough to prevent uplift under wave action. Additional research is required to confirm this.

In cooperation with the industry, integrated foundation design and installation methods should be evaluated in order to provide insight into the (economical) feasibility of applying collars to monopiles.

Furthermore, an interpretation is needed to translate the results obtained in the model to reality. Options to consider are scaling the number of waves or using a sediment transport based approach.

\section{REFERENCES}

Hoffmans, G.J.C.M., Verheij, H.C., (1997). "Scour Manual”. Balkema, Rotterdam, The Netherlands.

Kumar, V., Raju, K.G.R and Vittal, N., (1999). "Reduction of Local Scour around Bridge Piers Using Slots and Collars." Journal of Hydraulic Engineering. Vol I25. No 12. December 1999

Raaijmakers, T.C., Rudolph, D., (2008). "Time-dependent scour development under combined current and waves conditions - laboratory experiments with online monitoring technique." Fourth International Conference on Scour and Erosion, Tokyo 2008.

Rudolph, D., Raaijmakers, T.C., (2007). "Scour around jack-up legs with cone-shaped footings and skirts." Ilth International Conference "The Jack-Up. Platform Design, Construction \& Operation",11-12 September 2007, City University, London, England

Sheppard, D.M., Miller Jr., W., (2006). "Live-Bed Local Pier Scour Experiments". Journal of Hydraulic Engineering, Vol. 132, No. 7.

Simon, J.M., Johansen, N., Danyluk, R., (2009). "Design and Experimental Testing of New Scour Prevention Deveices for Offshore Wind Turbine Monopile foundations." Proceedings of European Offshore Wind Conference, Stockholm, Sweden, 14-16 September 2009.

Sumer, B.M., Fredsce, J., (2002). "The mechanics of scour in the marine environment." Advanced Series on Ocean Engineering - Volume 17. New Jersey: World Scientific.

Whitehouse, R.J.S. (1998). "Scour at marine structures". London: Thomas Telford Limited. 